\title{
Esophageal Heat Exchanger Versus Water-Circulating Cooling Blanket for Targeted Temperature Management
}

\author{
Daniel C. Schroeder, MD, ${ }^{1}$ Alexandra C. Maul, PhD, ${ }^{2}$ Maria Guschlbauer, PhD, ${ }^{2,3}$ Simon-Richard Finke, MD, \\ David de la Puente Bethencourt, MD, Tobias Neumann, MD, ${ }^{1}$ Stephan A. Padosch, MD, \\ Thorsten Annecke, MD, ${ }^{1}$ Bernd W. Böttiger, MD, ${ }^{1}$ Anja Sterner-Kock, PhD, ${ }^{2}$ and Holger Herff, MD ${ }^{1}$
}

To date, the optimal cooling device for targeted temperature management (TTM) remains unclear. Watercirculating cooling blankets are broadly available and quickly applied but reveal inaccuracy during maintenance and rewarming period. Recently, esophageal heat exchangers (EHEs) have been shown to be easily inserted, revealed effective cooling rates $\left(0.26-1.12^{\circ} \mathrm{C} / \mathrm{h}\right)$, acceptable deviations from target core temperature $\left(<0.5^{\circ} \mathrm{C}\right)$, and rewarming rates between 0.2 and $0.4^{\circ} \mathrm{C} / \mathrm{h}$. The aim of this study was to compare cooling rates, accuracy during maintenance, and rewarming period as well as side effects of EHEs with watercirculating cooling blankets in a porcine TTM model. Mean core temperature of domestic pigs $(n=16)$ weighing $83.2 \pm 3.6 \mathrm{~kg}$ was decreased to a target core temperature of $33^{\circ} \mathrm{C}$ by either using EHEs or watercirculating cooling blankets. After 8 hours of maintenance, rewarming was started at a goal rate of $0.25^{\circ} \mathrm{C} / \mathrm{h}$. Mean cooling rates were $1.3 \pm 0.1^{\circ} \mathrm{C} / \mathrm{h}$ (EHE) and $3.2 \pm 0.5^{\circ} \mathrm{C} / \mathrm{h}$ (blanket, $p<0.0002$ ). Mean difference to target core temperature during maintenance ranged between $\pm 1^{\circ} \mathrm{C}$. Mean rewarming rates were $0.21 \pm 0.01{ }^{\circ} \mathrm{C} / \mathrm{h}$ (EHE) and $0.22 \pm 0.02^{\circ} \mathrm{C} / \mathrm{h}$ (blanket, n.s.). There were no differences with regard to side effects such as brady- or tachycardia, hypo- or hyperkalemia, hypo- or hyperglycemia, hypotension, shivering, or esophageal tissue damage. Target temperature can be achieved faster by water-circulating cooling blankets. EHEs and water-circulating cooling blankets were demonstrated to be reliable and safe cooling devices in a prolonged porcine TTM model with more variability in EHE group.

Keywords: cardiac arrest, cooling, esophagus, induced hypothermia, targeted temperature management

\section{Introduction}

$\mathbf{S}_{\mathrm{o}}^{\mathrm{s}}$ UDDEN CARDIAC ARREST REMAINS the third leading cause of death in Europe and the industrialized nations (Böttiger et al., 2017). Known as targeted temperature management (TTM), decrease of the body's core temperature to $32-36^{\circ} \mathrm{C}$ for at least 24 hours after successful cardiopulmonary resuscitation is an established standard in critical care therapy. In fact, the metabolic rate of oxygen declines $7-10 \%$ per degree Celsius drop in temperature. Consequently, reactions associated with reperfusion injury will be suppressed and both neurologic outcome and survival can be improved (Polderman and Herold, 2009; Arrich et al., 2016).

To date, the optimal cooling device for TTM remains unclear. External cooling devices such as water-circulating cooling blankets are broadly available and quickly applied.
However, faster cooling rates and higher accuracy of maintenance temperature and rewarming rate can be achieved by use of intravascular cooling devices (IVDs) directly approaching the body's core blood. However, IVDs require expertise and are associated with major side effects including, for example, blood-stream infections and venous thromboembolism (Hoedemaekers et al., 2007; Sonder et al., 2018; Wang et al., 2018).

At present, esophageal heat exchangers (EHEs) are of scientific interest. Adjacent to the aorta, vena cava, and heart, the esophagus is an ideal place to exchange thermal energy to the body's core. EHEs have been shown to be easily inserted and do not damage esophageal tissue (Kulstad et al., 2013; Schroeder et al., 2017). Clinical trials demonstrated effective cooling rates $\left(0.26-1.12^{\circ} \mathrm{C} / \mathrm{h}\right)$, deviations $<0.5^{\circ} \mathrm{C}$ from target core temperature (Kulstad et al., 2013; Markota et al., 2016; Schroeder et al., 2017, 2018), and rewarming rates between

Departments of ${ }^{1}$ Anesthesiology and Intensive Care Medicine and ${ }^{2}$ Experimental Medicine, University Hospital of Cologne, Cologne, Germany.

${ }^{3}$ Decentral Animal Facility, University Hospital of Cologne, Cologne, Germany. 
$0.2^{\circ} \mathrm{C} / \mathrm{h}$ and $0.4^{\circ} \mathrm{C} / \mathrm{h}$ (Kulstad et al., 2013; Goury et al., 2017). To set the performance of EHEs in the context of commonly used cooling methods, the aim of this study was to compare EHEs with water-circulating cooling blankets in a porcine TTM model. The main study endpoints were cooling rates to a target core temperature of $33^{\circ} \mathrm{C}$, deviations from target core temperatures during the 8-hour maintenance period, and compliance to intended rewarming rates of $0.25^{\circ} \mathrm{C} / \mathrm{h}$. Esophageal tissue damage or other potential side effects were also examined in this prolonged experimental TTM protocol.

\section{Materials and Methods}

\section{Animal experiments}

The study was permitted by the local animal care committee and governmental authorities (Landesamt für Natur-, Umweltund Verbraucherschutz NRW; 84-02.04.2014.A157). The measures were in accordance with the German Federal Laws for Animal Protection and supervised by a veterinarian. The involved employees were qualified to guarantee adequate animal care and use. The study protocol and the present article comply with the Animals in Research: Reporting of In Vivo Experiments guidelines (Kilkenny et al., 2010).

Sixteen healthy, domestic adult pigs (Landrace $\times$ Pietrain) weighing $83.2 \pm 3.6 \mathrm{~kg}$ were used in this study. At least 10 days before conducting the experiments, animals were delivered to the facility, where they were kept in groups. Ambient temperatures were set to $20^{\circ} \mathrm{C}$ on a $12 / 12$-hour light/dark cycle, and straw-bedded pens $\left(9.3 \mathrm{~m}^{2}\right)$ were provided. Animals had ad libitum access to water and were fed twice a day with adequate nutrition.

\section{Perioperative management and anesthesia}

The night before the experiment, animals were fasted and isolated but maintained visual contact to the remaining group. After premedication with an intramuscular (i.m.) injection of azaperone ( $2 \mathrm{mg} / \mathrm{kg}$; Stresnil; Janssen, Neuss, Germany), ketamine (20 mg/kg; Ketavet 100; Pfizer, Berlin, Germany), and atropine $(0.02 \mathrm{mg} / \mathrm{kg}$; Braun, Melsungen, Germany), pigs were taken to the surgery room and received an intravenous (i.v.) catheter (Vasovet; Braun) in the lateral auricular vein. Animals were preoxygenated with $100 \%$ oxygen using a facial mask. Placed in a supine position, anesthesia was induced with propofol $(2 \mathrm{mg} / \mathrm{kg}$; Fresenius Kabi, Bad Homburg, Germany), and a $6.0 \mathrm{~mm}$ endotracheal tube (Teleflex Medical, Kernen, Germany) was inserted in the trachea by use of a $27 \mathrm{~cm}$ laryngoscope (Karl Storz, Tuttlingen, Germany). Pigs were ventilated with a tidal volume of $6 \mathrm{~mL} / \mathrm{kg}$ at 14 breaths/min (Fabius GS; Dräger, Lübeck, Germany) using a pressure-controlled mode (30\% oxygen). To maintain normocapnia (partial pressure of carbon dioxide, $40 \pm 5 \mathrm{mmHg}$ ), ventilation was adapted over time. After induction of anesthesia, animals received enrofloxacin (2.5 mg/kg i.m.; Baytril; Bayer, Leverkusen, Germany).

A standard lead II electrocardiogram was applied to monitor cardiac rhythm (Philips Medizinsysteme, Böblingen, Germany). To maintain anesthesia, propofol [5-7 mg/ $(\mathrm{kg} \cdot \mathrm{h})]$, midazolam $[1.2 \mathrm{mg} /(\mathrm{kg} \cdot \mathrm{h})$; Rotexmedica, Trittau, Germany], and fentanyl [12-15 $\mu \mathrm{g} /(\mathrm{kg} \cdot \mathrm{h})$; Fentanyl; Ro- texmedica] were continuously applied. Lactated Ringer's solution (Fresenius Kabi) at a rate of $5-10 \mathrm{~mL} /(\mathrm{kg} \cdot \mathrm{h})$ served as carrier and covered basic fluid requirement (Pehböck et al., 2015). In case of indications of reduced depth of anesthesia (hypertension, increased interdigital reflex, spontaneous breathing, and tachycardia), an additional bolus of propofol $(0.5-1 \mathrm{mg} / \mathrm{kg})$, midazolam $(0.02-0.03 \mathrm{mg} / \mathrm{kg})$, or fentanyl (1.0-1.25 $\mu \mathrm{g} / \mathrm{kg}$ ) was administered. In case of shivering, a bolus of rocuronium $(0.5 \mathrm{mg} / \mathrm{kg})$ was intended to be administered by the study protocol. Glucose $(250 \mathrm{~mL}$ Glucosteril $5 \%$; Fresenius Kabi) was applied if arterial blood glucose levels dropped below $3.5 \mathrm{mmol} / \mathrm{L}$. Norepinephrine [0.1 $\mu \mathrm{g} /(\mathrm{kg} \cdot \mathrm{min})$ i.v.; Arterenol; Sanofi-Aventis, Frankfurt am Main, Germany] was administered if mean arterial blood pressure decreased to $<50 \mathrm{mmHg}$.

\section{Surgical preparations}

During surgical preparation, animals were warmed using air-circulating blankets (Bairhugger; 3M Deutschland $\mathrm{GmbH}$, Neuss, Germany) to maintain a physiological core temperature $\left(38.5-39.5^{\circ} \mathrm{C}\right)$. The femoral artery was surgically exposed and a $6 \mathrm{~F}$ saline filled catheter (Arterial Leadercath; Vygon, Ecouen, France) was advanced for continuous blood pressure measurement (Philips M1097A; Philips Medizinsysteme) and collection of blood samples. The femoral vein was surgically exposed and a $7 \mathrm{~F}$ catheter (Arrow International, Reading, PA) was advanced for continuous drug application. In addition, the internal jugular vein was exposed and a $5 \mathrm{~F}$ saline filled catheter (Arrow International) was placed to measure the jugular blood temperature that highly reflects core temperature (Polderman and Herold, 2009). A $12 \mathrm{~F}$ catheter (Balloon Catheter; Teleflex Medical) was inserted into the bladder through suprapubic access to drain urine. Blood gas values were assessed regularly (ABLFlex800; Radiometer, Willich, Germany).

\section{Cooling systems}

After completion of surgical preparations, animals were randomized to an EHE or blanket group $(n=8)$. Subsequently, the catheter recording the jugular temperature was connected to a cooling device (HICO Variotherm 555; Hirtz \& Co KG, Cologne, Germany).

In the EHE group, an uninflated manufactured EHE was blindly inserted into the esophagus. Design, composition, and safety of the EHE were evaluated in previous studies by our group (Schroeder et al., 2017, 2018). In brief, the EHE consisted of medical silicone $600 \mathrm{~mm}$ in length with a diameter of $11 \mathrm{~mm}$. Within the tube, a forward and return flow supplied water from the cooling device and back, respectively. A third tube provided gastric suctioning. In the blanket group, two water-circulating cooling blankets (Hirtz \& Co KG) were applied below $(\varnothing 120 \times 70 \mathrm{~cm})$ and above $(\varnothing$ $50 \times 30 \mathrm{~cm})$ the pig. Both EHEs and water-circulating cooling blankets were perfused with purified water. Using a closedloop feedback system, the cooling device continuously registered core temperatures and adjusted the temperature of purified water to the requirements of the study protocol. Purified water was cooled to a minimum of $3^{\circ} \mathrm{C}$ and a maximum of $41^{\circ} \mathrm{C}$, which was considered to be safe previously (Laptook et al., 2014; Schroeder et al., 2018). 


\section{Experimental study protocol}

Ambient temperatures were measured by use of a Pt100 resistance thermometer (e.g., P-M-A-6-100-0-TS-2; Omega Engineering $\mathrm{GmbH}$, Deckenpfronn, Germany), which was placed in the surgery room. All temperatures were recorded continuously (Labview; National Instruments Germany, Munich, Germany). Hemodynamic and ventilation parameters were recorded in 15-minute intervals.

Before initiation of baseline measurements, air-circulating blankets were removed. Animals were cooled to a target core temperature of $33^{\circ} \mathrm{C}$ as fast as possible, which was maintained for 8 hours before initiation of rewarming with an intended rate of $0.25^{\circ} \mathrm{C} / \mathrm{h}$. At the end of the experiment, pigs were killed using an overdose of pentobarbital $(80 \mathrm{mg} / \mathrm{kg}$; Pentobarbital-Natrium; CP Pharma, Burgdorf, Germany) without regaining consciousness. Esophagi were resected and divided into four segments: laryngeal, cranial, medial, and caudal segment.

\section{Histopathology}

Esophagi of animals of both groups ( $n=8$ per group) were compared with the animals in the blanket group serving as control. Immediately after harvesting, esophageal tissue segments were fixed in $4 \%$ formalin for 24 hours and subsequently embedded in paraffin. Laryngeal, cranial, medial, and caudal esophageal segments were cut into slices of 2$3 \mu \mathrm{m}$ thickness. Afterward, slices were stained with hematoxylin and eosin on a glass slide. One slide of each segment was examined under light microscopy in $4 \times$ and $20 \times$ magnification (Olympus BX40; Olympus Deutschland GmbH, Hamburg, Germany). An animal pathologist blinded to the experimental setting assessed esophageal tissue damage according to a modified scoring protocol previously described (Lequerica et al., 2009; Schroeder et al., 2018). In brief, a numerical score for the following histological characteristics was assessed: epithelial hyperplasia, epithelial damage, edema (transmural), hyperemia, reactive submucosal glands, intraepithelial inflammation, and submucosal inflammation. Each location received a numerical score: 0 points: no specific findings, 1 point: focal tissue alteration, and 2 points: multifocal tissue alterations. Intraepithelial and submucosal inflammation received 0 points for no specific findings, 1 point if $<5$ mononuclear inflammatory cells per field were found and 2 points if $>5$ mononuclear inflammatory cells per field were found. The sum was calculated for each slice. Sum scores from 0 to 4 represented mild, 5-8 moderate, and $>9$ severe esophageal tissue damage (Schroeder et al., 2018).

\section{Statistical analysis}

All data were collected using Microsoft Excel 2010 (Microsoft Corporation, Redmond, WA). Calculations, statistical analysis, and graphing were performed with GraphPad Prism Version 8.0.0 (GraphPad Software, San Diego, CA). All data were expressed as mean \pm standard deviation (SD) if not stated otherwise. Esophageal damage score is ordinally scaled and was therefore described as median (lower quartile; upper quartile). Because of the small sample size, group differences were tested by the nonparametric Mann-Whitney $U$-test. Repeatedly measured variables were tested using two-way analysis of variance and post hoc Holm-Sídák tests. A value of $p<0.05$ was considered statistically significant.

\section{Results}

\section{Body weight and temperature profiles}

Mean body weights were $82.2 \pm 3.7 \mathrm{~kg}$ (EHE) and $84.4 \pm$ $3.8 \mathrm{~kg}$ (blanket, n.s.). Mean ambient temperatures during cooling period were $21.8 \pm 0.6^{\circ} \mathrm{C}$ (EHE) and $22.1 \pm 0.9^{\circ} \mathrm{C}$ (blanket, n.s.). Mean ambient temperatures during maintenance were $21.7 \pm 0.8^{\circ} \mathrm{C}(\mathrm{EHE})$ and $21.8 \pm 0.7^{\circ} \mathrm{C}$ (blanket, n.s.). Mean ambient temperatures during rewarming period were $21.7 \pm 0.6^{\circ} \mathrm{C}(\mathrm{EHE})$ and $22.1 \pm 0.7^{\circ} \mathrm{C}$ (blanket, n.s.). Mean entire time of placement of the cooling devices were $1130 \pm 36$ minutes (EHE) and $1181 \pm 17.6$ minutes (blanket, $p=0.0002)$. At initiation of cooling, mean core temperatures were $38.4 \pm 0.2^{\circ} \mathrm{C}(\mathrm{EHE})$ and $38.3 \pm 0.2^{\circ} \mathrm{C}$ (blanket, n.s.). Mean cooling rates were $1.3 \pm 0.1^{\circ} \mathrm{C} / \mathrm{h}(\mathrm{EHE})$ and $3.2 \pm$ $0.5^{\circ} \mathrm{C} / \mathrm{h}$ (blanket, $p<0.0002$; Fig. 1). Mean difference to target core temperatures during maintenance ranged between $\pm 1^{\circ} \mathrm{C}$ (Polderman and Herold, 2009) (Fig. 2). Mean rewarming rates were $0.21 \pm 0.01^{\circ} \mathrm{C} / \mathrm{h}(\mathrm{EHE})$ and $0.22 \pm$ $0.02^{\circ} \mathrm{C} / \mathrm{h}$ (blanket, n.s.; Fig. 1).

\section{Hemodynamic and electrolytes}

Mean heart rate and mean arterial blood pressure were not significantly different between the groups during the entire TTM protocol (Supplementary Figs. S1 and S2). Mean \pm SD throughout the whole experimentation for sodium were $141.1 \pm 1.9 \mathrm{mmol} / \mathrm{L}(\mathrm{EHE})$ and $140.3 \pm 1.6 \mathrm{mmol} / \mathrm{L}$ (blanket, n.s.; Supplementary Fig. S3). Chloride levels were 112.3 \pm $4.9 \mathrm{mmol} / \mathrm{L}$ (EHE) and $109.9 \pm 4.3 \mathrm{mmol} / \mathrm{L}$ (blanket, n.s.;

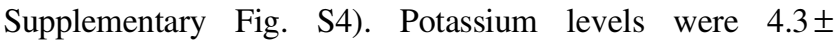
$0.2 \mathrm{mmol} / \mathrm{L}$ (EHE) and $4.3 \pm 0.2 \mathrm{mmol} / \mathrm{L}$ (blanket, n.s.; Supplementary Fig. S5). Calcium levels were $1.43 \pm 0.05 \mathrm{mmol} / \mathrm{L}$ (EHE) and $1.41 \pm 0.03 \mathrm{mmol} / \mathrm{L}$ (blanket, n.s.; Supplementary Fig. S6). pHs were $7.40 \pm 0.04$ (EHE) and 7.41 \pm 0.03 (blanket, n.s.; Supplementary Fig. S7). Base excesses were $0.45 \pm$ $2.49 \mathrm{mmol} / \mathrm{L}$ (EHE) and $1.7 \pm 2.06 \mathrm{mmol} / \mathrm{L}$ (blanket, n.s.; Supplementary Fig. S8). Hematocrit levels were $23.1 \pm 0.9 \%$ (EHE) and 23.2 $\pm 0.8 \%$ (blanket, n.s.; Supplementary Fig. S9). Blood glucose levels were $4.0 \pm 0.1 \mathrm{mmol} / \mathrm{L}$ (EHE) and $4.2 \pm 0.2 \mathrm{mmol} / \mathrm{L}$ (blanket, n.s.; Supplementary Fig. S10).

\section{Side effects}

Shivering was not detected in any group during the entire TTM protocol. Thus, muscle relaxation using rocuronium could be avoided in all animals. There were no clinically relevant differences in brady- or tachycardia, hypo- or hyperkalemia, hypo- or hyperglycemia, hypotension, or overcooling.

\section{Histopathology}

We did not detect relevant esophageal tissue damage (Fig. 3). Median damage scores were $6[3 ; 6]$ (EHE) and 5 [3.25; 5.75] (blanket, n.s.) for laryngeal esophageal segments, 3 [2; 3] (EHE) and 4 [3; 5] (blanket, n.s.) for upper esophageal segments, 2.5 [1.25; 3.75] (EHE) and 3 [1.25; 4] (blanket, n.s.) for medial esophageal segments, and $2[1 ; 3]$ 


\section{Core Temperature}

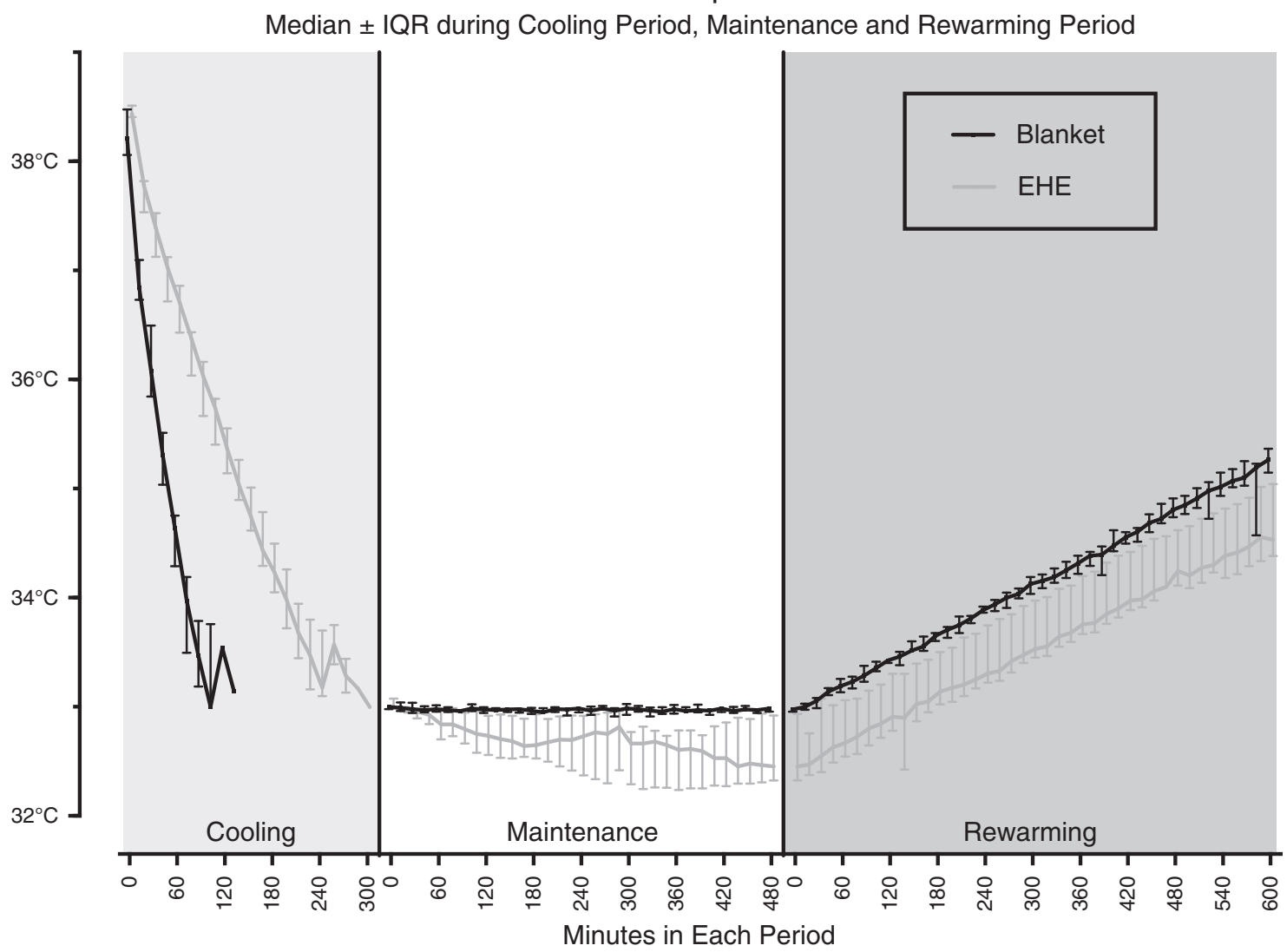

FIG. 1. Temperature profile. Median $\pm \mathrm{IQR}$ of core temperature in ${ }^{\circ} \mathrm{C}$ during the entire targeted temperature management protocol. EHEs, esophageal heat exchangers; IQR, interquartile range.

(EHE) and 1 [1; 2.5] (blanket, n.s.) for lower esophageal segments. Occasional mild mononuclear acute inflammatory transepithelial infiltrates were found in laryngeal esophageal segments in both groups but not in other tissue segments.

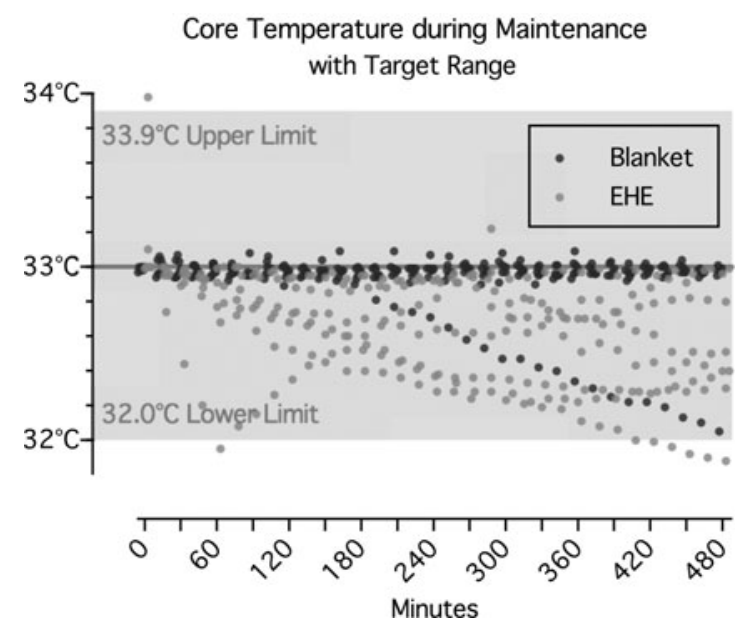

FIG. 2. Variability of core temperature during maintenance. Core temperature in ${ }^{\circ} \mathrm{C}$ during maintenance for each individual randomized to EHE or blanket group. The gray area indicates the target range from $32^{\circ} \mathrm{C}$ to $33.9^{\circ} \mathrm{C}$ (Polderman and Herold, 2009).

\section{Discussion}

In this prolonged experimental TTM study protocol use of water-circulating cooling blankets resulted in faster cooling rates than EHEs. Both devices met the prerequisites during maintenance and rewarming period but with more variability in EHE group. No clinically relevant esophageal tissue damage or other relevant side effects were observed.

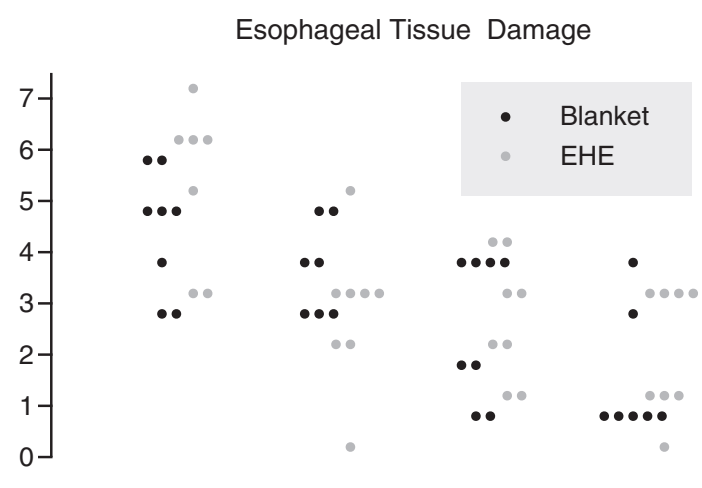

Laryngeal Upper Esot Middle Eso Lower Eso

FIG. 3. Esophageal tissue damage score. Adapted esophageal tissue damage score for each individual randomized to EHE or blanket group. 
Despite enormous scientific efforts, the most advantageous cooling method and the optimal time to reach the target core temperature after cardiac arrest still remains unclear (Nolan et al., 2015; Kim et al., 2018). There is scientific evidence that rapid cooling after cardiac arrest may be favorable to reduce cerebral damage (Bernard et al., 2002; Polderman and Herold, 2009; Che et al., 2011). On the contrary, faster decline of the core temperature predicts poor neurological outcome (Haugk et al., 2011). Thus, evaluation of cooling rates is of major importance in choice of the adequate cooling method and was the focus in this study.

Interestingly, surface cooling rates in this study exceeded surface cooling rates of human studies by three times (Hoedemaekers et al., 2007). However, narcotized swine suffer from undesired surface cooling of $\sim 4.8^{\circ} \mathrm{C} / \mathrm{h}$ (Dingley et al., 2018). In addition, cooling rates of $\sim 8-12^{\circ} \mathrm{C} / \mathrm{h}$ are also reported by other groups evaluating cooling blankets in pigs (Haugk et al., 2010; Weihs et al., 2011). Haugk et al. (2010) even reported a faster cooling rate of $8^{\circ} \mathrm{C} / \mathrm{h}$ by surface cooling compared with endovascular cooling in pigs. We conclude that multiple factors may influence cooling rates by surface cooling in pigs: (1) weight and age (Haugk et al., 2010), (2) structural differences to the human skin such as bristles, higher amount of subcutaneous fat, and less vasculature (ElKattan et al., 2000), (3) higher resting metabolism (Pehböck et al., 2014), and (4) a relatively large body surface of adult pigs (Kelley et al., 1973). Although our model with body weights corresponding to adults $(>80 \mathrm{~kg})$ is as close to human conditions as possible, porcine models may be overly sensitive for surface cooling, which significantly affected our results.

In the present and previous experimental studies, EHE reached cooling rates between $1.2^{\circ} \mathrm{C} / \mathrm{h}$ and $2.8^{\circ} \mathrm{C} / \mathrm{h}$ depending on the weight of the pigs (Kulstad et al., 2013; Schroeder et al., 2017, 2018). Finally, extrapolation to clinical conditions may reveal cooling rates considered to be effective for neuroprotection (Polderman and Herold, 2009). However, clinical data containing four patients after return of spontaneous circulation and one study involving 17 comatose survivors after out of hospital cardiac arrest point toward lower cooling rates $\left(0.26-0.42^{\circ} \mathrm{C} / \mathrm{h}\right)$ achievable by EHE compared with water-circulating cooling blankets (Moulaert et al., 2009; Goury et al., 2017; Hegazy et al., 2017; Kim et al., 2018). Thus, further clinical studies are needed to demonstrate benefits of EHE in patients suffering from cardiac arrest and other therapeutic indications for TTM.

Our aim was to simulate a TTM protocol as close as possible to critical care conditions. Thus, after reaching the target core temperature, we maintained this temperature for 8 hours and simulated rewarming at a rate of $0.25^{\circ} \mathrm{C} / \mathrm{h}$ as is actually recommended. Although the rewarming rate was comparable in both groups, higher temperature fluctuations during maintenance $\left(>0.5^{\circ} \mathrm{C}\right)$ were demonstrated in the EHE group, which could lead to long-term side effects such as pneumonia and wound infections. Interestingly, EHEs were comparably effective during maintenance in other studies (Kulstad et al., 2012, 2013; Naiman et al., 2016; Hegazy et al., 2017; Schroeder et al., 2017, 2018; Khan et al., 2018). As discussed above, the porcine model with its characteristics may have also influenced maintenance period, which could explain deviations from target core temperature in this study.

One major concern using the EHE may be possible esophageal tissue damage during long-term exposure to cold or heat. The EHE remained in place for at least 18 hours in this "prolonged" study simulating the situation in the critical care unit. Even in this prolonged setting we did not detect clinically relevant esophageal tissue damage, which is in accordance to previous studies (Kulstad et al., 2013; Schroeder et al., 2017). Presumably, food-related mild mononuclear acute transepithelial invasion of inflammatory cells leads to higher esophageal tissue damage in laryngeal segments, which is reported to be a physiological process (Desai et al., 2005) and in line with other studies investigating EHE in porcine models (Schroeder et al., 2017, 2018). Mild laryngeal tissue damage is also conceivable during endotracheal intubation in $80 \mathrm{~kg}$ pigs demonstrating prominent throat tissue, which was, however, uncomplicated in this study. Furthermore, we did not observe any other unwanted side effects such as brady- or tachycardia, hypo- or hyperkalemia, hypo- or hyperglycemia, hypotension, hypoxemia, or shivering (Buse et al., 2017).

Several limitations have to be considered. First, this study was conducted in the absence of cardiac arrest. The core temperature is mainly dependent on neurologic damage (Perman et al., 2015) and impaired hemodynamics. Both were at a physiological level in our study, which may have influenced performance of cooling and rewarming. Finally, there is a large body of evidence that general anesthetics such as fentanyl, propofol, and midazolam affect vegetative thermoregulatory control and decrease core temperature (Sessler, 2008). To avoid inhomogeneous baseline temperatures, we reduced perioperative hypothermia during surgical preparation by covering and actively rewarming the pigs with aircirculating blankets. Thereby, we were able to confirm clinical data in a controlled experimental environment.

\section{Conclusions}

Target temperature can be achieved faster by watercirculating cooling blankets. EHEs and water-circulating cooling blankets were demonstrated to be reliable and safe cooling devices in a prolonged porcine TTM model with more variability in the EHE group. EHE may usefully supplement cooling methods for TTM.

\section{Acknowledgments}

We are thankful to Manuela Lerwe and Irmgard Henke, Center for Experimental Medicine, University Hospital of Cologne, Cologne, Germany for their particular expertise in histopathological tissue preparation. We also thank Karsten Ehlert; Hirtz \& Co. KG, Cologne, Germany for his technical expertise. This work was supported by "The Central Innovation Program for Small and Medium-sized enterprises," German Federal Ministry for Economic affairs and Energy (KF2429611AK3) (H.H.). Equipment and funding was provided by Hirtz \& Co. KG, Cologne, Germany.

\section{Author Disclosure Statement}

B.W.B. is European Resuscitation Council Board Director Science and Research; Chairman of the German Resuscitation Councils (GRC); Member of the "Advanced Life Support" Task Force of the International Liaison Committee on Resuscitation; Member of the executive committee of the German Interdisciplinary Association for Intensive and emergency Medicine (DIVI); Associate Editor of the European 
Journal of Anaesthesiology, Co-Editor of "Resuscitation"; Editor of the journal "Notfall + Rettungsmedizin." He received professional fees for lectures from the following companies: Medupdate, Forum for Medizinische Fortbildung, Baxalta, Bayer Vita, Zoll, BARD. T.A. received research grants sponsored by Corpuls, CytoSorbens, Pulsion, Medtronic, Köhler Chemie, Centre of Integrated Oncology Köln-Bonn (CIO). H.H., D.S., T.A., and T.N. received funding from the "The Central Innovation Program for Small and Medium-sized enterprises," German Federal Ministry for Economic affairs and Energy. This work was supported by Hirtz \& Co. KG, Cologne, Germany (Equipment). No author received charges, and so forth, from industrial partners or from a third party. No author has any financial or personal relationship with other people or organizations that could inappropriately influence this work.

\section{Supplementary Material}

Supplementary Figure S1

Supplementary Figure S2

Supplementary Figure S3

Supplementary Figure S4

Supplementary Figure S5

Supplementary Figure S6

Supplementary Figure S7

Supplementary Figure S8

Supplementary Figure S9

Supplementary Figure S10

\section{References}

Arrich J, Holzer M, Havel C, Mullner M, Herkner H. Hypothermia for neuroprotection in adults after cardiopulmonary resuscitation. Cochrane Database Syst Rev 2016;2: CD004128.

Bernard SA, Gray TW, Buist MD, Jones BM, Silvester W, Gutteridge G, et al. Treatment of comatose survivors of outof-hospital cardiac arrest with induced hypothermia. N Engl J Med 2002;346:557-563.

Böttiger BW, Semeraro F, Altemeyer KH, Breckwoldt J, Kreimeier U, Rucker G, et al. KIDS SAVE LIVES: school children education in resuscitation for Europe and the world. Eur J Anaesthesiol 2017;34:792-796.

Buse S, Blancher M, Viglino D, Pasquier M, Maignan M, Bouzat $\mathrm{P}$, et al. The impact of hypothermia on serum potassium concentration: a systematic review. Resuscitation 2017;118:35-42.

Che D, Li L, Kopil CM, Liu Z, Guo W, Neumar RW. Impact of therapeutic hypothermia onset and duration on survival, neurologic function, and neurodegeneration after cardiac arrest. Crit Care Med 2011;39:1423-1430.

Desai TK, Stecevic V, Chang CH, Goldstein NS, Badizadegan K, Furuta GT. Association of eosinophilic inflammation with esophageal food impaction in adults. Gastrointest Endosc 2005;61:795-801.

Dingley J, Okano S, Planas S, Chakkarapani E. Feasibility of a miniature esophageal heat exchange device for rapid therapeutic cooling in newborns: preliminary investigations in a piglet model. Ther Hypothermia Tem Manag 2018;8:36-44.

El-Kattan A, Asbill CS, Haidar S. Transdermal testing: practical aspects and methods. Pharm Sci Technol Today 2000;3:426430.
Goury A, Poirson F, Chaput U, Voicu S, Garcon P, Beeken T, et al. Targeted temperature management using the "Esophageal Cooling Device" after cardiac arrest (the COOL study): a feasibility and safety study. Resuscitation 2017;121: 54-61.

Haugk M, Krizanac D, Stratil P, Grassberger M, Weihs W, Testori C, et al. Comparison of surface cooling and invasive cooling for rapid induction of mild therapeutic hypothermia in pigs - effectiveness of two different devices. Resuscitation 2010;81:1704-1708.

Haugk M, Testori C, Sterz F, Uranitsch M, Holzer M, Behringer $\mathrm{W}$, et al. Relationship between time to target temperature and outcome in patients treated with therapeutic hypothermia after cardiac arrest. Crit Care 2011;15:R101.

Hegazy AF, Lapierre DM, Butler R, Martin J, Althenayan E. The esophageal cooling device: a new temperature control tool in the intensivist's arsenal. Heart Lung 2017;46:143148.

Hoedemaekers CW, Ezzahti M, Gerritsen A, van der Hoeven JG. Comparison of cooling methods to induce and maintain normo- and hypothermia in intensive care unit patients: a prospective intervention study. Crit Care 2007;11:R91.

Kelley KW, Curtis SE, Marzan GT, Karara HM, Anderson CR. Body surface area of female swine. J Animal Sci 1973;36: 927-930.

Khan I, Haymore J, Barnaba B, Armahizer M, Melinosky C, Bautista MA, et al. Esophageal cooling device versus other temperature modulation devices for therapeutic normothermia in subarachnoid and intracranial hemorrhage. Ther Hypothermia Tem Manag 2018;8:53-58.

Kilkenny C, Browne WJ, Cuthill IC, Emerson M, Altman DG. Improving bioscience research reporting: the ARRIVE guidelines for reporting animal research. PLoS Biol 2010;8: e1000412.

Kim KH, Shin SD, Song KJ, Ro YS, Kim YJ, Hong KJ, et al. Cooling methods of targeted temperature management and neurological recovery after out-of-hospital cardiac arrest: a nationwide multicenter multi-level analysis. Resuscitation 2018;125:56-65.

Kulstad E, Metzger AK, Courtney DM, Rees J, Shanley P, Matsuura $\mathrm{T}$, et al. Induction, maintenance, and reversal of therapeutic hypothermia with an esophageal heat transfer device. Resuscitation 2013;84:1619-1624.

Kulstad EB, Courtney DM, Waller D. Induction of therapeutic hypothermia via the esophagus: a proof of concept study. World J Emerg Med 2012;3:118-122.

Laptook AR, Kilbride H, Shepherd E, McDonald SA, Shankaran S, Truog W, et al. Temperature control during therapeutic hypothermia for newborn encephalopathy using different Blanketrol devices. Ther Hypothermia Temp Manag 2014;4:193-200.

Lequerica JL, Sanz E, Hornero F, Herrero M, Ruiz N, Burdio F, et al. Esophagus histological analysis after hyperthermiainduced injury: implications for cardiac ablation. Int $\mathbf{J}$ Hyperthermia 2009;25:150-159.

Markota A, Fluher J, Kit B, Balazic P, Sinkovic A. The introduction of an esophageal heat transfer device into a therapeutic hypothermia protocol: a prospective evaluation. Am J Emerg Med 2016;34:741-745.

Moulaert VR, Verbunt JA, van Heugten CM, Wade DT. Cognitive impairments in survivors of out-of-hospital cardiac arrest: a systematic review. Resuscitation 2009;80:297-305.

Naiman M, Shanley P, Garrett F, Kulstad E. Evaluation of advanced cooling therapy's esophageal cooling device for 
core temperature control. Expert Rev Med Devices 2016;13: 423-433.

Nolan JP, Soar J, Cariou A, Cronberg T, Moulaert VR, Deakin $\mathrm{CD}$, et al. European Resuscitation Council and European Society of Intensive Care Medicine Guidelines for postresuscitation care 2015: section 5 of the European Resuscitation Council Guidelines for Resuscitation 2015. Resuscitation 2015; 95:202-222.

Pehböck D, Dietrich H, Klima G, Paal P, Lindner KH, Wenzel V. Anesthesia in swine: optimizing a laboratory model to optimize translational research. Anaesthesist 2015;64:65-70.

Perman SM, Ellenberg JH, Grossestreuer AV, Gaieski DF, Leary M, Abella BS, et al. Shorter time to target temperature is associated with poor neurologic outcome in post-arrest patients treated with targeted temperature management. Resuscitation 2015;88:114-119.

Polderman KH, Herold I. Therapeutic hypothermia and controlled normothermia in the intensive care unit: practical considerations, side effects, and cooling methods. Crit Care Med 2009;37:1101-1120.

Schroeder DC, Guschlbauer M, Maul AC, Cremer DA, Becker I, de la Puente Bethencourt D, et al. Oesophageal heat exchangers with a diameter of $11 \mathrm{~mm}$ or $14.7 \mathrm{~mm}$ are equally effective and safe for targeted temperature management. PLoS One 2017;12:e0173229.

Schroeder DC, Maul AC, Guschlbauer M, Finke SR, de la Puente Bethencourt D, Becker I, et al. Intravascular cooling device versus esophageal heat exchanger for mild therapeutic hypo- thermia in an experimental setting. Anesth Analg 2018 [Epub ahead of print]; DOI: 10.1213/ANE.0000000000003922.

Sessler DI. Temperature monitoring and perioperative thermoregulation. Anesthesiology 2008;109:318-338.

Sonder P, Janssens GN, Beishuizen A, Henry CL, Rittenberger JC, Callaway CW, et al. Efficacy of different cooling technologies for therapeutic temperature management: a prospective intervention study. Resuscitation 2018;124:14-20.

Wang X, Moy BT, Hiendlmayr BJ, Krainski F, Duvall WL, Fernandez AB. Intravascular cooling catheter-related venous thromboembolism after hypothermia: a case report and review of the literature. Ther Hypothermia Tem Manag 2018;8: 117-120.

Weihs W, Schratter A, Sterz F, Janata A, Hogler S, Holzer M, et al. The importance of surface area for the cooling efficacy of mild therapeutic hypothermia. Resuscitation 2011;82: 74-78.

Address correspondence to:

Daniel C. Schroeder, MD

Department of Anesthesiology and Intensive Care Medicine University Hospital of Cologne

Kerpener Straße 62

Köln D-50937

Germany

E-mail: daniel.schroeder@uk-koeln.de 